\title{
Leishmania infantum HSP70-II null mutant as candidate vaccine against leishmaniasis: a preliminary evaluation
}

\author{
Javier Carrión, Cristina Folgueira, Manuel Soto, Manuel Fresno and Jose M Requena*
}

\begin{abstract}
Background: Visceral leishmaniasis is the most severe form of leishmaniasis and no effective vaccine exists. The use of live attenuated vaccines is emerging as a promising vaccination strategy.

Results: In this study, we tested the ability of a Leishmania infantum deletion mutant, lacking both HSP70-II alleles $(\triangle H S P 70-I I)$, to provide protection against Leishmania infection in the L. major-BALB/C infection model.

Administration of the mutant line by either intraperitoneal, intravenous or subcutaneous route invariably leads to the production of high levels of $\mathrm{NO}$ and the development in mice of type 1 immune responses, as determined by analysis of anti-Leishmania IgG subclasses. In addition, we have shown that $\triangle H S P 70-I I$ would be a safe live vaccine as immunodeficient SCID mice, and hamsters (Mesocricetus auratus), infected with mutant parasites did not develop any sign of pathology.
\end{abstract}

Conclusions: The results suggest that the $\triangle H S P 70-\|$ mutant is a promising and safe vaccine, but further studies in more appropriate animal models (hamsters and dogs) are needed to appraise whether this attenuate mutant would be useful as vaccine against visceral leishmaniasis.

\section{Background}

Leishmaniasis is a vector-borne disease that is caused by the infection of protozoan parasites of the genus Leishmania. The extracellular promastigote forms of Leishmania are inoculated into humans (and other mammalian hosts) by sandflies (phlebotomine insects), after which the parasites undergo phagocytosis by macrophages and transform to intracellular amastigotes. Clinical manifestations of leishmaniasis are particularly diverse [1], ranging from subclinical (unapparent infections) to visceral leishmaniasis (VL), which is usually fatal when untreated. Other common forms of the disease are mucocutaneous (MCL), diffuse cutaneous (DCL) and cutaneous leishmaniasis $(\mathrm{CL})$. The clinical outcomes depends upon a number of factors, including the species (and strain) of the parasite, as well as the host's genetically determined immune responses. Thus, Leishmania major and many other Leishmania species cause CL, Leishmania donovani and Leishmania infantum are mainly associated with VL, whereas

\footnotetext{
* Correspondence: jmrequena@cbm.uam.es

Centro de Biología Molecular "Severo Ochoa" (CSIC-UAM), Universidad Autónoma de Madrid, Madrid, Spain
}

(c) 2011 Carrión et al; licensee BioMed Central Ltd. This is an Open Access article distributed under the terms of the Creative Commons Attribution License (http://creativecommons.org/licenses/by/2.0), which permits unrestricted use, distribution, and reproduction in any medium, provided the original work is properly cited.
MCL results after infection with parasites from the Leishmania braziliensis complex [2].

Leishmaniasis threatens 350 million people worldwide, mainly in developing countries. Annual incidence is estimated at 2 million cases and the overall prevalence is 12 million people [3]. In developing and under-developed parts of the world, AIDS and other immunosuppressive syndromes add to the higher risk of leishmaniasis [4]. In spite of its incidence, leishmaniasis is a neglected disease. Current control strategies rely on reservoir and vector control and pharmacological drugs, but new treatment strategies are clearly needed [5]. Abundant clinical and experimental evidence indicates that leishmaniasis would be preventable by vaccination, but anti-leishmanial vaccines for human use have yet to be developed [6-10].

Effective vaccination against human CL has been practiced for centuries by deliberate inoculation of living organisms from the exudates of active lesions or, more recently, by the inoculation of cultured Leishmania promastigotes (process known as "leishmanization") [11]. The appearance of complications, i.e. developing of severe disease in some individuals, led to abandoning the 
use of live Leishmania as a prophylactic vaccine. Nevertheless, leishmanization is still currently practiced in some countries including Uzbekistan, Afghanistan, Iraq, and Iran [12], and there are recent efforts to standardize it as a live vaccine and also to use it for rapidly assessing the efficacy of new vaccines [13]. On the other hand, first generation vaccines (or killed vaccines), prepared using inactivated whole parasites, have been the subject of many studies over decades and are the only vaccine candidates for leishmaniasis which have undergone phase 3 clinical trials. However, evidence of protective efficacy has not emerged from those clinical trials [14].

The ineffectiveness of vaccines based on either killed parasites or recombinant proteins seems to be a consequence of the short-term immunity they induce [15]. On the other hand, several studies in mice indicate that persistent parasites are important to maintain durable, antiLeishmania memory responses $[12,16]$. These findings have led to the exploration of the use of live, genetically modified-parasites as an appealing strategy for developing vaccines against leishmaniasis $[17,18]$. Defined genetic alterations of the Leishmania genome can be achieved through homologous recombination [19], allowing disruption of essential genes for virulence and/or host survival. The first Leishmania mutant generated by gene replacement assayed as a potential Leishmania vaccine was an L. major line lacking the gene coding for dihydrofolate reductase-thymidylate synthase (DHFR-TS) [20]. This thymidine-auxotroph mutant was found to persist in BALB/c mice for up to 2 months, but it was incapable of causing disease. Interestingly, this $d h f r$-ts knockout was able to elicit substantial resistance in mice to a subsequent challenge with virulent $L$. major. However, immunizations with $d h f r-$ ts knockouts derived from L. chagasi, L. donovani, or $L$. major did not protect against $L$. chagasi infection in $\mathrm{BALB} / \mathrm{c}$ mice [21]. In another report, disruption of $B T 1$ genes, encoding a biopterin transporter, in Leishmania donovani allowed the generation of a mutant line with reduced capacity for inducing infection in mice [22]. Furthermore, it was found that inoculation of BT1 null parasites elicits protective immunity in mice against an L. donovani challenge. Another mutant assayed as attenuated vaccine has been an L. major LPG2-knockout, which cannot synthesize LPG and other phosphoglycans; despite this defect, upon infection of mice, the mutants persist for several months without causing disease [23]. When BALB/ c mice infected with lpg2- parasites were challenged with virulent L. major, they were protected from disease [24]. However, the in vivo follow-up of these mutants led to the identification of a compensatory mutant (lpg2-REV) that regained virulence even in the absence of phosphoglycan synthesis [25]. In addition, it was found that L. mexicana $\operatorname{lpg} 2^{-}$mutants retained their virulence for macrophages and mice [26]. Another genetically-modified L. mexicana line, lacking cysteine proteinase genes $c p a$ and $c p b$, was successfully used to protect against homologous infection in mice and hamsters $[27,28]$. Likewise, vaccination of BALB/c mice with an L. mexicana null mutant for GDPmannose pyrophosphorylase (GDP-MP) conferred significant and long lasting protection against infection with virulent parasites [29]. Recently, it has been shown that BALB/c mouse infection with L. infantum mutant lacking one of the two SIR2 (silent information regulatory 2) alleles induced a high degree of protection against a virulent challenge [30]. More recently, it was reported that immunization with a centrin deletion mutant of L. donovani protected mice against infection with either L. donovani or L. braziliensis [31].

In this study, we analyzed the inmunoprotective ability of an L. infantum deletion mutant, lacking HSP7O type II gene $(\triangle \mathrm{HSP} 70-\mathrm{II})$, as a live vaccine against leishmaniasis in the L. major-BALB/c infection model. Immunization with this mutant line elicited specific immune responses and significant levels of protection against a challenge with virulent $L$. major promastigotes.

\section{Methods}

\section{Animals and parasites}

Experiments were performed in accordance with procedures approved by the Spanish Research Council Bioethics Committee. For animal experimentation, we followed the ethical principles dictated by the European Commission (Directive 86/609/CEE) for use of laboratory animals.

Female BALB/c and BALB SCID (CB-17 $7^{\text {scid }}$ ) mice (6-8 week old), and male hamsters (Mesocricetus auratus; 8 week old) were purchased from Harlan Interfauna Iberica S.A. (Barcelona, Spain) and maintained in specificpathogen-free facilities.

The $\Delta$ HSP70-II null mutant ( $\Delta h s p 70-I I:: N E O / \Delta h s p 70$ $I I:: H Y G)$ is a cloned line that was generated by targeted deletion of both HSP70-II alleles in the L. infantum strain MCAN/ES/96/BCN150 [32]. L. major promastigotes (strain MHOM/IL/80/Friedlin; clon V1) were also used in this study. Promastigotes of both species were grown in RPMI 1640 culture medium supplemented with $10 \%$ heat-inactivated FBS, $100 \mathrm{U} / \mathrm{ml}$ penicillin and $100 \mu \mathrm{g} / \mathrm{ml}$ streptomycin.

\section{Infections}

The virulence of $L$. infantum and L. major parasites was maintained by passage in hamsters and BALB/c mice, respectively. For infections, amastigote-derived promastigotes with less than 3 passages in vitro were used. For infection of mice with the $\Delta$ HSP70-II mutant $\left(10^{7}\right.$ promastigotes/mouse), three routes were assayed: intravenous (IV; tail-vein injection), intraperitoneal (IP), and 
subcutaneous (SC; right hind-footpad). Mice from the control groups were inoculated with $0.1 \mathrm{ml}$ of PBS.

Hamsters were infected with $5 \times 10^{7} \Delta$ HSP70-II promastigotes by the intracardiac route (IC) as described elsewhere [33]. Age- and sex-matched hamsters were maintained uninfected and used as control for immunological determinations.

L. major metacyclic promastigotes were purified from stationary phase cultures. Briefly, promastigotes were resuspended in phosphate buffer saline (PBS) at $10^{8}$ cells/ $\mathrm{ml}$, and peanut agglutinin (Vector laboratories) was added at $50 \mu \mathrm{g} / \mathrm{ml}$; the sample was incubated for $25 \mathrm{~min}$ at room temperature. After centrifugation at $900 \times \mathrm{g}$ for $10 \mathrm{~min}$, the supernatant contained the non-agglutinated metacyclic promastigotes. A thousand of metacyclic promastigotes in $50 \mu \mathrm{l}$ were injected in the right hind-footpad of BALB/c mice. The growth of the lesion was monitored at indicated time points by measuring the thickness of the footpad using a dial caliper. The contralateral footpad of each animal represented the control value and the swelling calculated as: thickness of the right footpad - thickness of the left footpad.

Determination of the tissue parasite burden was carried out by quantitative limiting-dilution as described by Buffet and co-workers [34]. Briefly, whole lymph nodes, spleens and weighed pieces of liver were individually homogenized in Schneider's medium supplemented with $20 \%$ inactivated-FBS, $100 \mathrm{U} / \mathrm{ml}$ penicillin and $100 \mu \mathrm{g} / \mathrm{ml}$ streptomycin. The homogenates, in quadruplicate, were serially diluted across 96-well plates. Wells were examined for the presence of motile parasites after 2 (for L. major) or 4 (for L. infantum) weeks of culturing at $26^{\circ} \mathrm{C}$. The number of parasites per organ was calculated as follows: parasite burden $=$ (geometric mean of titer from quadruplicate cultures) $\times$ (reciprocal fraction of the homogenized organ inoculated into the first well). The titer was the reciprocal of the last dilution in which parasites were observed.

\section{Analysis of antibody responses}

A Leishmania crude antigen was prepared from L. infantum promastigotes by incubation of microorganisms in lysis buffer (1\% Triton X-100, $150 \mathrm{mM} \mathrm{NaCl}$, $10 \mathrm{mM}$ Tris- $\mathrm{HCl} \mathrm{pH} 8$ and $1 \mathrm{mM}$ PMSF) for $15 \mathrm{~min}$. Afterwards, the suspension, kept on ice, was sonicated until a decrease in viscosity was observed. The insoluble material was pelleted at $10000 \times \mathrm{g}$ for $5 \mathrm{~min}$ and the supernatant was immediately stored at $-70^{\circ} \mathrm{C}$ until use.

Sera were taken from all groups of mice before and 4 weeks after inoculation of the $\Delta$ HSP70-II promastigotes. Serum samples were analyzed for specific antibodies against Leishmania total antigen by standard ELISA assay. Briefly, standard plates (NUNC A/S, Roskilde, Denmark) were coated overnight at $4^{\circ} \mathrm{C}$ with $100 \mu$ of Leishmania crude antigen $(2 \mu \mathrm{g} / \mathrm{ml}$ in PBS). The sera from mice were assayed using two-fold serial dilutions. As secondary antibodies the following peroxidase-conjugates (Nordic Immunology Laboratories, Tilburg, The Netherlands) were used: goat anti-mouse IgG1 (1:1000 dilution) and goat anti-mouse IgG2a (1:1000 dilution). Orthophenylenediamine dihydrochloride (DAKO A/S, Glostrup, Denmark) was used as a peroxidase substrate. After $30 \mathrm{~min}$, the reaction was stopped by the addition of $100 \mu \mathrm{l}$ of $1 \mathrm{M} \mathrm{H}_{2} \mathrm{SO}_{4}$, and the absorbance was read at $450 \mathrm{~nm}$. Titer was calculated as the reciprocal of the serum dilution that gave an absorbance above the mean value of preimmune sera plus three standard deviations.

Antibody responses in hamsters were determined by ELISA using the same antigen and coating conditions indicated above. The primary sera were assayed at 1:200 dilution, and the secondary antibody (RAHa/IgG(H+L)/ PO conjugate; Nordic) was used at 1:1500 dilution.

\section{Nitric oxide (NO) determinations}

Peritoneal macrophages from the different groups of mice (either control or infected with the $\triangle$ HSP70-II mutant by different routes, see above) were cultured at a concentration of $10^{6}$ cells per milliliter in RPMI 1640 culture medium supplemented with $10 \%$ heat-inactivated $\mathrm{FBS}, 100 \mathrm{U} / \mathrm{ml}$ penicillin and $100 \mu \mathrm{g} / \mathrm{ml}$ streptomycin. Soluble Leishmania antigen (SLA; see below) was added to a final concentration of $50 \mu \mathrm{g} / \mathrm{ml}$. After $48 \mathrm{~h}$ of incubation at $37^{\circ} \mathrm{C}$, cell-free supernatants were collected and the nitrite level was stimulated using the Griess reaction kit (Sigma-Aldrich) according to the manufacturer's protocol. The basal NO production by murine macrophages was determined after culturing of the cells in the absence of SLA.

\section{Lymphoproliferation assays}

At nine months after infection with $\triangle$ HSP70-II promastigotes, hamsters $(n=4)$ were euthanized and single cell suspensions from the spleens were made. Splenocytes from age- and sex-matched hamsters were used as controls. Cells $\left(2.5 \times 10^{6} / \mathrm{ml}\right)$ were plated in 96 -well plates $(200 \mu \mathrm{l})$ in RPMI medium supplemented with $10 \%$ heatinactivated FBS, $100 \mathrm{U} / \mathrm{ml}$ penicillin and $100 \mu \mathrm{g} / \mathrm{ml}$ streptomycin. Cells were stimulated with either Concanavalin A (ConA; $1 \mu \mathrm{g} / \mathrm{ml})$ or SLA $(10 \mu \mathrm{g} / \mathrm{ml})$ for $72 \mathrm{~h}$. As control, unstimulated cultures were maintained in parallel. Proliferation was evaluated after addition of $1 \mu \mathrm{Ci}$ of $\left[{ }^{3} \mathrm{H}\right]$ thymidine $(5 \mathrm{Ci} / \mathrm{mmol})$ for the last $16-\mathrm{h}$ of incubation. Incorporation of thymidine was assessed by scintillation counting.

SLA was prepared by three freezing and thawing cycles of stationary promastigotes of L. infantum suspended in PBS. After cell lysis, soluble antigens were separated from the insoluble fraction by centrifugation for $15 \mathrm{~min}$ at $12,000 \times \mathrm{g}$. 


\section{Results and discussion Inoculation of $\triangle \mathrm{HSP} 70-$ Il parasites protects BALB/c mice against $L$. major challenge}

In a previous work [35], we found that L. infantum parasites lacking the HSP70-II gene ( $\triangle$ HSP70-II) have a virulence greatly reduced. Thus, after infection of BALB/c mice with 10 millions of $\triangle H S P 70-I I$ promastigotes, the parasite loads in liver and spleen were more than 1000-fold lower than those achieved after infection with wildtype (WT) parasites. Nevertheless, the immune response elicited in mice by the infection with $\triangle$ HSP70II parasites showed immunoprotective features. Thus, even though mice infected with $\triangle$ HSP70-II promastigotes had low levels of Leishmania-specific antibodies, the IgG2a/IgG1 ratio was higher in $\triangle$ HSP70-II infected mice than in mice infected with the WT promastigotes [35]. IgG2a dominance in the immune response is associated with protective responses against Leishmania infection [36].

To investigate whether $\Delta$ HSP70-II parasites would provide protection to leishmaniasis, we used the L. major-BALB/c infection model. In many ways, the infection of BALB/c mice with $L$. major may be a better model for human VL than for CL [37,38]. These mice develop high antibody titers, and the parasites frequently metastasize to distant locations including the bone marrow, liver, and spleen. Similar to human $\mathrm{VL}, \mathrm{BALB} / \mathrm{c}$ mice typically succumb to infection with L. major [39]. Nevertheless, it should be clearly stated that the hamster and the dog are better animal models than the mouse for human VL [40]. For the experiment, mice were intravenously infected with $10^{7}$ $\triangle$ HSP70-II promastigotes, and 4 weeks later were challenged in the footpad with 1000 L. major metacyclics. Control mice developed large, nonhealing cutaneous lesions and had to be euthanized after 7 weeks. In contrast, mice previously infected with $\triangle$ HSP70-II parasites displayed a resistance phenotype: a reduced inflammation was observed in one mouse, and no lesions appeared in the rest of mice (Figure 1A). Mice were sacrificed and the parasite burden determined in the draining popliteal lymph node and spleen by limiting dilution (Figure 1B). In agreement with lesion progression, mice previously infected with $\triangle$ HSP70-II parasites had fewer parasites than controls; the differences were particularly dramatic when comparing the parasite loads in the spleen. Dissemination of $L$. major parasites to internal organs correlates with susceptibility in the mouse infection model [38]. Thus, inoculation of $L$. major promastigotes into the dermis or the footpad of BALB/c mice leads to the dissemination of the parasite, after a short period (10-24 hours), to the spleen, the liver, the bone marrow, and, occasionally, the kidney. However, in similarly infected mouse strains with a curative phenotype like C57BL/6, CBA/J, and $\mathrm{C} 3 \mathrm{H} / \mathrm{HeJ}$, the parasites remain localized in the footpad and in the draining popliteal lymph node for many days without evidence of dissemination. In conclusion, the results indicated that an effective protection was attained in BALB/c mice infected with the $\Delta$ HSP70-II mutant.

\section{Immunological and parasitological parameters associated with the inoculation route}

The above experiments demonstrate that IV inoculation with $\triangle$ HSP70-II parasites confers a significant protection against $L$. major infection in mice. In a new set of experiments, we compared the immunological responses observed after inoculation of the mutant by three inoculation routes: intraperitoneal (IP), IV and subcutaneous (SC). We first focused on the humoral immune response and determined the titers of IgG1 and IgG2a antibodies against Leishmania proteins by ELISA before and 4 weeks after inoculation of the mutant line in all three groups. As shown in Figure 2A, the IgG2a titers were higher than IgG1 titers for all groups, suggesting that infection with $\triangle$ HSP70-II parasites, independent of the inoculation route, leads to a predominant production of anti-Leishmania antibodies of the IgG2a isotype. Although inoculation through the IV route leads to considerably higher titers (2-4 fold) of IgG2a antibodies in comparison to the other inoculation routes (Figure 2A), the highest IgG2a/IgG1 was observed in mice infected through the $\mathrm{SC}$ route. IgG2a antibody formation is dependent on IFN- $\gamma$ as an IgM-to-IgG2a switch factor and is considered to be typical for a $\mathrm{T}$ helper type 1 (Th1) response; in contrast, IgG1 production depends on IL-4 secreted by Th2 cells [41].

Because the production of NO by macrophages is a key factor in killing Leishmania, we determined also the level of NO produced by peritoneal macrophages from $\triangle$ HSP70-II infected mice after in vitro re-stimulation with SLA. Interestingly, significant levels of nitrites were observed in the culture supernatants of macrophages of the three infection-groups when compared with control macrophages (Figure 2B). Nevertheless, production of NO was clearly higher by SLA-stimulated macrophages from mice infected with $\triangle$ HSP70-II parasites through the IP route.

Finally, we analyzed the parasite burden in spleen and liver of the different groups of $\triangle$ HSP70-II infected mice (Figure 2C). No parasites were detected in BALB/c mice four weeks after infection through the SC route suggesting that the $\triangle$ HSP70-II mutant was unable to visceralize. On the other hand, the parasite burden was higher when the mutant is inoculated through the IV route 


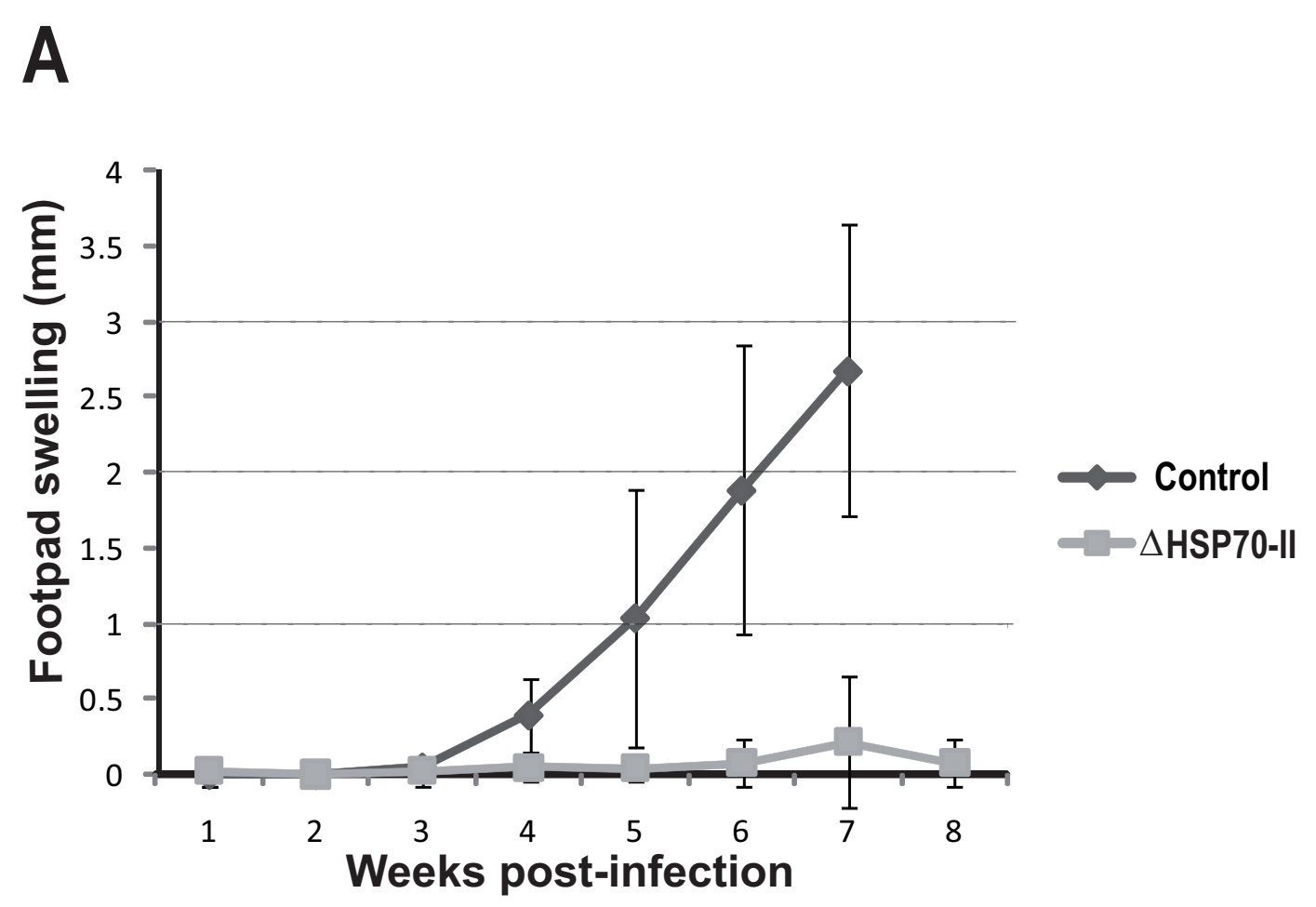

B

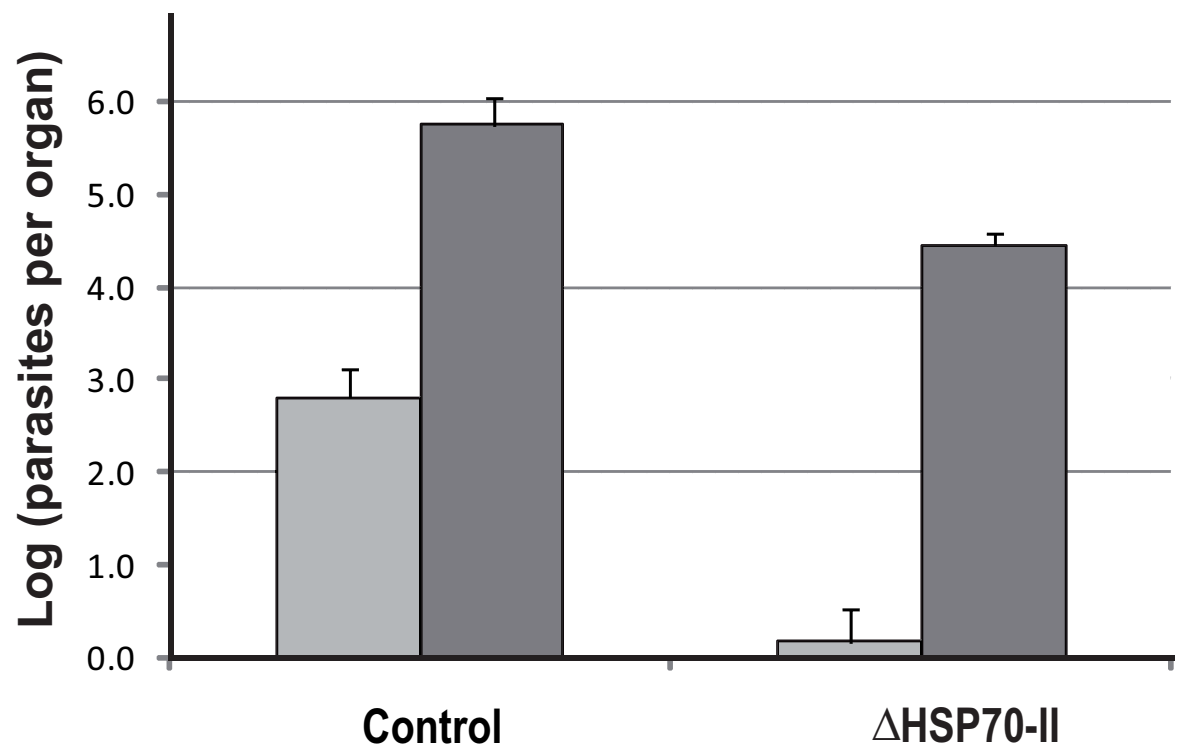

$\square$ Spleen 口LN

Figure 1 Course of L.major infection in BALB/c mice vaccinated with $\triangle$ HSP70-II promastigotes. BALB/C mice $(n=5)$ were inoculated with $1 \times 10^{7} \Delta$ HSP70-II promastigotes and, 4 weeks later, challenged with 1,000 metacyclic promastigotes of $L$. major. The control group (unvaccinated) was challenged with an identical inoculum of L. major. (A) Course of lesion progression. (B) Parasite burdens in spleen and popliteal lymph node (right foot). The data presented are representative of two experiments with similar results. 




B

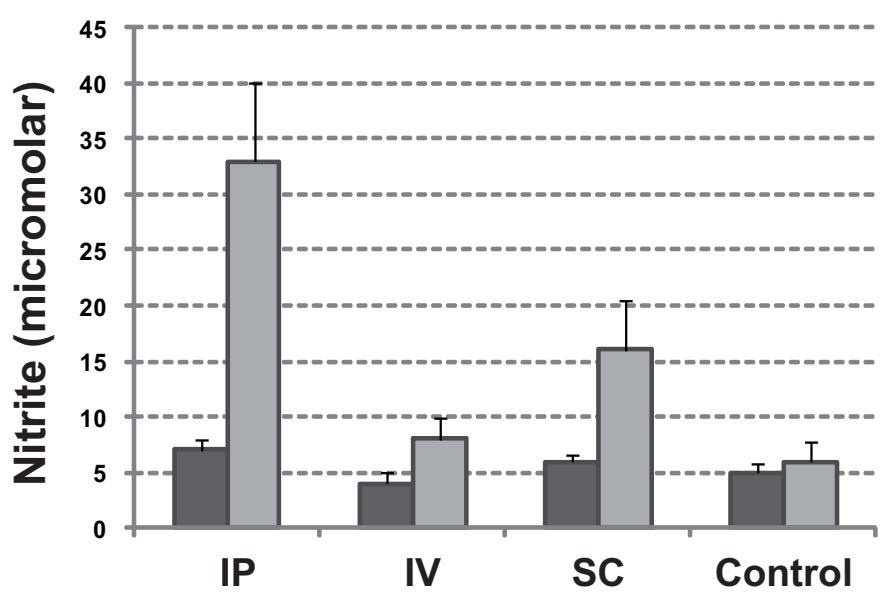

Medium

口SLA

C

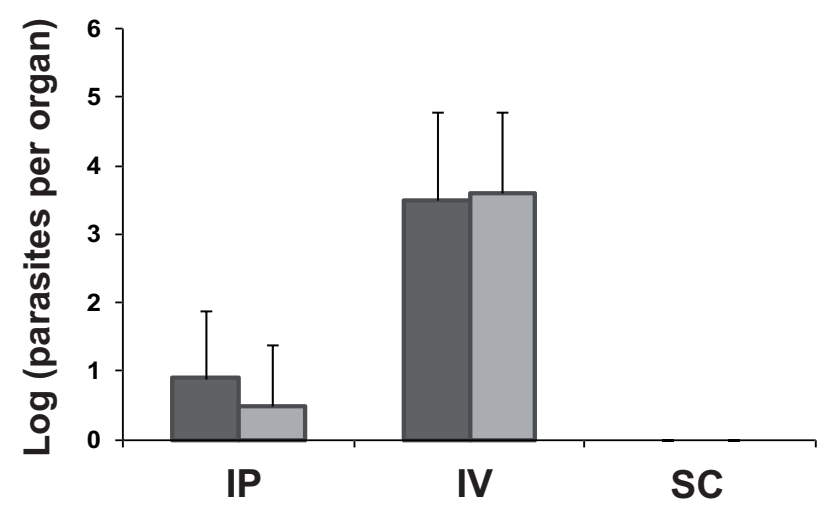

Figure 2 Immunological and parasitological parameters associated with the inoculation route of $\triangle$ HSP70-II promastigotes in BALB/C mice. Groups of mice $(n=4)$ were inoculated with $1 \times 10^{7} \Delta$ HSP70-II promastigotes by the intraperitoneal (IP), intravenous (IV) or subcutaneous (SC) route. (A) Four weeks after infection the anti-Leishmania specific IgG1 and IgG2a titers were determined by ELISA. Differences between IgG1 and IgG2a titers for each group of mice were compared by using the two-tailed paired Student's t-test: ${ }^{*}, p=0.016 ;{ }^{* *}, p=0.066 ;{ }^{* * *}, p=0.019$. (B) Production of NO by peritoneal macrophages from $\triangle$ HSP70-II infected (IP, IV, and SC) or control mice. (C) Parasite burdens in spleen and liver of $\triangle$ HSP70-II infected mice. The data are represented as the mean + standard deviation. 
than when the mutant is inoculated into the peritoneal cavity.

\section{$\triangle H S P 70-I I$ parasites are highly attenuated in susceptible L. infantum animal models}

Before considering the $\triangle$ HSP70-II mutant line as a candidate vaccine, it is critical that the parasites remains attenuated, and that a selection of escape variants, in which the infectivity is restored, does not occur as a consequence of continuous passage in BALB/c mice. Spontaneous recovery of virulence has been observed for some attenuated Leishmania mutants, e.g. $\operatorname{lpg} 2^{-}$[25], LmxPK4- [42], and hsp100- [43].

The $\Delta$ HSP70-II mutant line was created in 2005 [32]; since then, the parasite has been used many times to infect $\mathrm{BALB} / \mathrm{c}$, and recovery of virulence has not been observed (see also Figures 2 and 3). To further explore whether the $\triangle$ HSP70-II parasites would remain attenuated in the absence of a functional immune system, SCID mice lacking functional $\mathrm{T}$ and $\mathrm{B}$ cells were infected. As shown in Figure 3, SCID mice infected with $\triangle$ HSP70-II promastigotes showed even lower parasite burdens than $\triangle$ HSP70-II-infected BALB/c mice (this is especially true for the liver). At first glance this result may be considered unexpected; however, after carefully revising previous studies on Leishmania infection of SCID mice, our findings may be expected. Certainly, the parasite burdens in SCID mice are higher than those observed in immunocompetent mice, but it is true at long-term. However, if the parasite burdens are determined at short-term, the parasitemia is lower in the SCID mice than in the BALB/c $[30,44]$. The reason may be in the fact that SCID mice, perhaps as a compensatory mechanism due to the lack of functional $\mathrm{T}$ and $\mathrm{B}$ cells, have a relatively higher potential of functional NK cells (see Solbach and Laskay [39] for further details). As the $\triangle$ HSP70-II line has an intrinsic low capacity of multiplication in mammalian hosts, the higher activity or levels of NK cells in SCID may explain why the parasite loads are lower in SCID mice than in BALB/c mice.

On the other hand, in the initial experiments of $\mathrm{BALB} / \mathrm{c}$ infection with this mutant line, no parasites were recovered in the liver [35]; thus, it is likely that the $\Delta$ HSP70-II parasite has evolved a liver tropism after in vivo passing. Nevertheless, it should always be kept in mind that the parasite burdens in $\triangle$ HSP70-II infected $\mathrm{BALB} / \mathrm{c}$ mice were three to four orders of magnitude lower than those found in mice infected with the L. infantum parental strain (BCN150); as reported previously [35], at 4 weeks post-infection, the total burdens

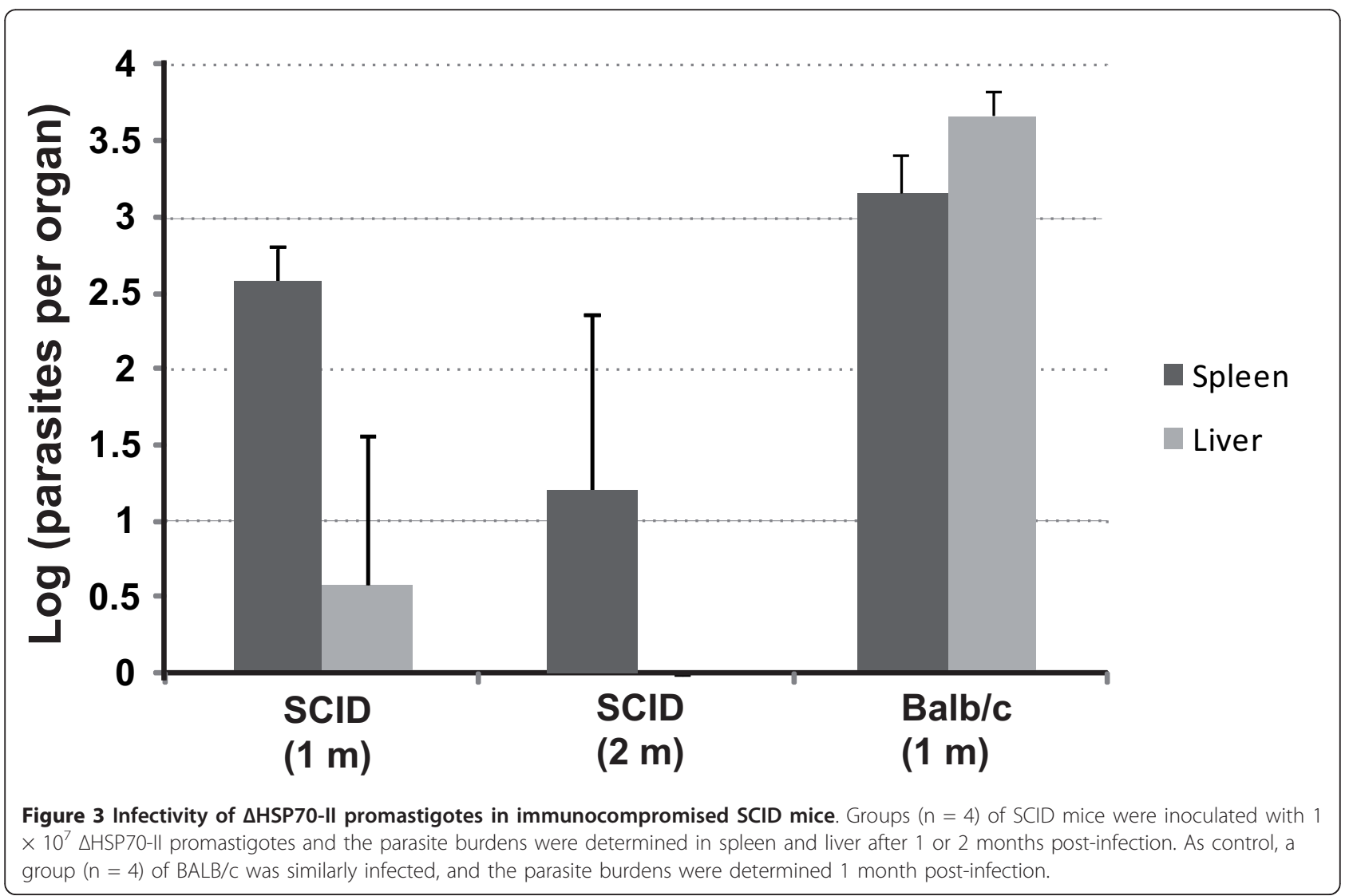


per organ, in BCN150-infected BALB/c mice, were around 2 million (6.3 logarithmic units) in spleen, and 80 million (7.9 logarithmic units) in liver. Even more interestingly, we found that parasite burdens in $\triangle$ HSP70-II-infected SCID declined at two months postinfection and parasites were not detected in the liver at this time (Figure 3). This finding demonstrates that $\triangle$ HSP70-II parasites cannot replicate efficiently even in immunocompromised SCID mice, which otherwise when infected with $L$. infantum WT parasites develop a progressive parasitemia [30]. Together, those results confirm that $\triangle$ HSP70-II parasites would constitute a safe vaccine.

Inbred strains of mice are not adequate models for infectivity analysis of viscerotropic strains of Leishmania, as mice naturally develop protective immunity against the infection that leads to a clearance of the parasite [45]. Thus, we further assessed the virulence of the $\Delta$ HSP70-II mutant in the golden hamster ( $M$. auratus) model, which is a laboratory animal that accurately reproduce pathological aspects of human VL, such as an uncontrolled parasite replication in the liver and spleen $[33,46]$. Furthermore, golden hamsters are so susceptible for $L$. infantum infection that infective doses as low as 1000 parasites result in fatal disease [33].

A group of four hamsters were intracardially inoculated with 50 million $\triangle$ HSP70-II promastigotes and the animals were examined weekly for clinical symptoms of disease progression. Additionally, at two-month intervals, blood samples were obtained and the humoral response against Leishmania was assayed. Although weak, a specific anti-SLA antibody response was detected at two months post-infection in all animals (data not shown). Afterwards, the IgG reactivity decreased slightly, but a specific response still remained detectable at 9 months post-infection (Table 1). Apart from this, no other signs of infection were observed in the $\triangle$ HSP70-II-infected hamsters; instead the animals remained healthy. At this point, 9 months post-infection, animals were sacrificed and individually analyzed for the present of parasites in liver and spleen by limiting dilution. No parasites were found in any of the tissues, and the organs showed a normal morphology. In parallel, the capacity of spleen cells, from infected and control hamsters, to proliferate in the presence of parasite antigens was assessed (Table 1). Remarkably, splenocytes from $\Delta$ HSP70-II-infected hamsters specifically proliferated in response to Leishmania antigens (2-3 fold above control cells). Furthermore, splenocytes of $\triangle$ HSP70-II-infected hamsters showed a proliferation capacity, similar to control animals, after stimulating with the mitogen ConA (Table 1). It should be noticed that infection of hamsters with virulent $L$. donovani (and also with L. infantum; our unpublished data) leads to a significant suppression of the ability of spleen cells to respond to ConA [47]. In summary, these data suggest that inoculation with the $\triangle$ HSP70-II mutant was able to elicit a long-lasting immune response, without affecting the normal function of the immune system.

\section{Conclusions}

A vaccine against leishmaniasis seems to be feasible since most individuals that were once infected with Leishmania become resistant to clinical infection when later exposed to the parasite. However, despite great research effort, leishmanization with live Leishmania parasites remains the only vaccine with proven efficacy against human leishmaniasis. Genetic modification of Leishmania to reduce virulence, yet maintaining immunogenicity, is of current interest in vaccine research. According to the levels of IgG1 and IgG2a antibodies, and the NO production, the immunization of mice with the $\triangle$ HSP70-II deletion mutant appears to be eliciting predominantly Th1 responses, independently of the route of administration (intraperitoneal, intravenous or subcutaneous). In addition, we found that immunization of BALB/c with $\triangle$ HSP70-II promastigotes lead to an effective immune response able to protect these mice against infection with L. major.

In summary, present results offer hope for the development of a live-attenuated vaccine against Leishmania based on this mutant line. However, we are aware that this work constitutes a preliminary study and that further experiments, using more appropriate models for LV (hamsters and/or dogs), are needed. An important concern with live-attenuated vaccines is their safety, as there are fears that the parasite may revert back to a virulent form or cause lesions in immunesuppressed individuals. Interestingly, the low numbers of parasites found after infection with $\triangle$ HSP70-II promastigotes in hamsters, BALB/c mice and even in SCID mice (lacking both $\mathrm{T}$ and B cells) support the idea that this mutant would be a safe vaccine, which might be helpful to design prevention

Table 1 Immunological responses elicited in golden hamsters infected with $\Delta$ HSP70-II parasites

\begin{tabular}{|c|c|c|c|c|}
\hline \multicolumn{5}{|c|}{ Proliferation \pm SD $(c p m)^{a}$} \\
\hline & IgG reactivity ${ }^{a}$ & Medium & SLA & ConA \\
\hline Uninfected & $0.12 \pm 0.01$ & $4444 \pm 840$ & $4467 \pm 674$ & $230427 \pm 14932$ \\
\hline$\triangle H S P 70-\|$ & $0.25 \pm 0.03$ & $4646 \pm 763$ & $9515 \pm 1953$ & $264887 \pm 12337$ \\
\hline
\end{tabular}

${ }^{\mathrm{a}}$ See Methods for experimental details 
strategies against Leishmania infection in both dogs and humans [48]. Additionally, based on this safety, this $\Delta$ hsp70-II line could also have usefulness as a platform for introduction of immunoprotective antigens relevant to leishmaniasis or even to other diseases.

\section{Acknowledgements}

The careful revision of two anonymous reviewers and their suggestions are appreciated. This work was supported by grants from the Ministerio de Ciencia y Tecnología (BFU2009-08986) and the Fondo de Investigaciones Sanitarias (ISCIII-RETIC RD06/0021/0008-FEDER) to JMR, and Comunidad Autónoma de Madrid (S-SAL-0159-2006), Ministry of Science and Innovation of Spain (SAF2007-61716 and SAF2010-18733), "Red Tematica de Investigación en Enfermedades cardiovasculares" (RECAVA RD06/0014/1013); "Red de Investigación de Centros de Enfermedades Tropicales" (RICET RD06/ 0021/0016) to MF. Also, an institutional grant from Fundación Ramón Areces is acknowledged.

\section{Authors' contributions}

JC carried out most of the experimental procedures. CF constructed the $\triangle H S P 70-I I$ mutant line. MS and JMR performed immunoproliferation assays. MF and JMR conceived the research, contributed with data analysis and revision of the manuscript. JMR wrote the manuscript. All authors read and approved the final version of the manuscript.

\section{Competing interests}

The authors declare that they have no competing interests.

Received: 14 May 2011 Accepted: 27 July 2011 Published: 27 July 2011

\section{References}

1. Murray HW, Berman JD, Davies CR, Saravia NG: Advances in leishmaniasis. Lancet 2005, 366(9496):1561-1577.

2. Pearson RD, de Queiroz Sousa A: Clinical spectrum of Leishmaniasis. Clin Infect Dis 1996, 22(1):1-13.

3. Desjeux P: Leishmaniasis: current situation and new perspectives. Comp Immunol Microbiol Infect Dis 2004, 27(5):305-318.

4. Cruz I, Nieto J, Moreno J, Cañavate C, Desjeux P, Alvar J: Leishmania/HIV co-infections in the second decade. Indian J Med Res 2006, 123(3):357-388.

5. Chappuis F, Sundar S, Hailu A, Ghalib H, Rijal S, Peeling RW, Alvar J, Boelaert M: Visceral leishmaniasis: what are the needs for diagnosis, treatment and control? Nat Rev Microbiol 2007, 5(11):873-882.

6. Ghosh M, Bandyopadhyay S: Present status of antileishmanial vaccines. Mol Cell Biochem 2003, 253(1-2):199-205.

7. Requena JM, Iborra S, Carrion J, Alonso C, Soto M: Recent advances in vaccines for leishmaniasis. Expert Opin Biol Ther 2004, 4(9):1505-1517.

8. Khamesipour A, Rafati S, Davoudi N, Maboudi F, Modabber F: Leishmaniasis vaccine candidates for development: a global overview. Indian J Med Res 2006, 123(3):423-438

9. Kedzierski L, Zhu Y, Handman E: Leishmania vaccines: progress and problems. Parasitology 2006, 133(Suppl):S87-112.

10. Palatnik-de-Sousa CB: Vaccines for leishmaniasis in the fore coming 25 years. Vaccine 2008, 26(14):1709-1724.

11. Dunning N: Leishmania vaccines: from leishmanization to the era of DNA technology. BioscienceHorizons 2009, 2(1):73-82.

12. Okwor I, Uzonna J: Persistent parasites and immunologic memory in cutaneous leishmaniasis: implications for vaccine designs and vaccination strategies. Immunol Res 2008, 41(2):123-136.

13. Khamesipour A, Dowlati Y, Asilian A, Hashemi-Fesharki R, Javadi A, Noazin S, Modabber F: Leishmanization: use of an old method for evaluation of candidate vaccines against leishmaniasis. Vaccine 2005, 23(28):3642-3648.

14. Noazin S, Modabber F, Khamesipour A, Smith PG, Moulton LH, Nasseri K Sharifi I, Khalil EA, Velez-Bernal ID, Antunes CMF, et al: First generation leishmaniasis vaccines: a review of field efficacy trials. Vaccine 2008, 26(52):6759-6767.

15. Okwor I, Liu D, Uzonna J: Qualitative differences in the early immune response to live and killed Leishmania major: Implications for vaccination strategies against Leishmaniasis. Vaccine 2009, 27(19):2554-2562.

16. Belkaid Y, Piccirillo CA, Mendez S, Shevach EM, Sacks DL: CD4+CD25+ regulatory $T$ cells control Leishmania major persistence and immunity. Nature 2002, 420(6915):502-507.

17. Selvapandiyan A, Duncan R, Debrabant A, Lee N, Sreenivas G, Salotra P, Nakhasi HL: Genetically modified live attenuated parasites as vaccines for leishmaniasis. Indian J Med Res 2006, 123(3):455-466.

18. Silvestre R, Cordeiro-da-Silva A, Ouaissi A: Live attenuated Leishmania vaccines: a potential strategic alternative. Arch Immunol Ther Exp (Warsz) 2008, 56(2):123-126.

19. Beverley SM: Protozomics: trypanosomatid parasite genetics comes of age. Nat Rev Genet 2003, 4(1):11-19

20. Titus RG, Gueiros-Filho FJ, de Freitas LA, Beverley SM: Development of a safe live Leishmania vaccine line by gene replacement. Proc Natl Acad SCl USA 1995, 92(22):10267-10271.

21. Streit JA, Recker TJ, Filho FG, Beverley SM, Wilson ME: Protective immunity against the protozoan Leishmania chagasi is induced by subclinical cutaneous infection with virulent but not avirulent organisms. J Immunol 2001, 166(3):1921-1929.

22. Papadopoulou B, Roy G, Breton M, Kundig C, Dumas C, Fillion I, Singh AK, Olivier M, Ouellette M: Reduced infectivity of a Leishmania donovan biopterin transporter genetic mutant and its use as an attenuated strain for vaccination. Infect Immun 2002, 70(1):62-68.

23. Spath GF, Lye L-F, Segawa H, Sacks DL, Turco SJ, Beverley SM: Persistence without pathology in phosphoglycan-deficient Leishmania major. Science 2003, 301(5637):1241-1243.

24. Uzonna JE, Spath GF, Beverley SM, Scott P: Vaccination with phosphoglycan-deficient Leishmania major protects highly susceptible mice from virulent challenge without inducing a strong Th1 response. J Immunol 2004, 172(6):3793-3797.

25. Spath GF, Lye LF, Segawa H, Turco SJ, Beverley SM: Identification of a compensatory mutant (Ipg2-REV) of Leishmania major able to survive as amastigotes within macrophages without LPG2-dependent glycoconjugates and its significance to virulence and immunization strategies. Infect Immun 2004, 72(6):3622-3627.

26. Ilg T, Demar M, Harbecke D: Phosphoglycan repeat-deficient Leishmania mexicana parasites remain infectious to macrophages and mice. J Biol Chem 2001, 276(7):4988-4997.

27. Alexander J, Coombs GH, Mottram JC: Leishmania mexicana cysteine proteinase-deficient mutants have attenuated virulence for mice and potentiate a Th1 response. J Immunol 1998, 161(12):6794-6801.

28. Saravia NG, Escorcia B, Osorio Y, Valderrama L, Brooks D, Arteaga L, Coombs G, Mottram J, Travi BL: Pathogenicity and protective immunogenicity of cysteine proteinase-deficient mutants of Leishmania mexicana in non-murine models. Vaccine 2006, 24(19):4247-4259.

29. Stewart J, Curtis J, Spurck TP, Ilg T, Garami A, Baldwin T, Courret N, McFadden Gl, Davis A, Handman E: Characterisation of a Leishmania mexicana knockout lacking guanosine diphosphate-mannose pyrophosphorylase. Int J Parasitol 2005, 35(8):861-873.

30. Silvestre R, Cordeiro-Da-Silva A, Santarem N, Vergnes B, Sereno D, Ouaissi A: SIR2-deficient Leishmania infantum induces a defined IFN-gamma/L-10 pattern that correlates with protection. J Immunol 2007, 179(5):3161-3170.

31. Selvapandiyan A, Dey R, Nylen S, Duncan R, Sacks D, Nakhasi HL: Intracellular replication-deficient Leishmania donovani induces long lasting protective immunity against visceral leishmaniasis. J Immunol 2009, 183(3):1813-1820.

32. Folqueira C, Quijada L, Soto M, Abanades DR, Alonso C, Requena JM: The translational efficiencies of the two Leishmania infantum HSP70 mRNAs, differing in their $3^{\prime}$-untranslated regions, are affected by shifts in the temperature of growth through different mechanisms. J Biol Chem 2005, 280(42):35172-35183.

33. Requena JM, Soto M, Doria MD, Alonso C: Immune and clinical parameters associated with Leishmania infantum infection in the golden hamster model. Vet Immunol Immunopathol 2000, 76(3-4):269-281.

34. Buffet PA, Sulahian A, Garin YJ, Nassar N, Derouin F: Culture microtitration: a sensitive method for quantifying Leishmania infantum in tissues of infected mice. Antimicrob Agents Chemother 1995, 39(9):2167-2168.

35. Folgueira C, Carrion J, Moreno J, Saugar JM, Cañavate C, Requena JM: Effects of the disruption of the HSP70-II gene on the growth, 
morphology, and virulence of Leishmania infantum promastigotes. Int Microbiol 2008, 11(2):81-89.

36. Wilson ME, Jeronimo SMB, Pearson RD: Immunopathogenesis of infection with the visceralizing Leishmania species. Microb Pathog 2005, 38(4):147-160.

37. Handman E: Leishmaniasis: current status of vaccine development. Clin Microbiol Rev 2001, 14(2):229-243.

38. Solbach W, Laskay T: The host response to Leishmania infection. Adv Immunol 2000, 74:275-317.

39. Miles SA, Conrad SM, Alves RG, Jeronimo SMB, Mosser DM: A role for lgG immune complexes during infection with the intracellular pathogen Leishmania. J Exp Med 2005, 201(5):747-754.

40. Solano-Gallego L, Miro G, Koutinas A, Cardoso L, Pennisi MG, Ferrer L, Bourdeau P, Oliva G, Baneth G: LeishVet guidelines for the practical management of canine leishmaniosis. Parasit Vectors 2011, 4(1):86.

41. Raz E, Tighe H, Sato Y, Corr M, Dudler JA, Roman M, Swain SL, Spiegelberg HL, Carson DA: Preferential induction of a Th1 immune response and inhibition of specific lgE antibody formation by plasmid DNA immunization. Proc Natl Acad Sci USA 1996, 93(10):5141-5145.

42. Kuhn D, Wiese M: LmxPK4, a mitogen-activated protein kinase kinase homologue of Leishmania mexicana with a potential role in parasite differentiation. Mol Microbiol 2005, 56(5):1169-1182.

43. Reiling L, Jacobs T, Kroemer M, Gaworski I, Graefe S, Clos J: Spontaneous recovery of pathogenicity by Leishmania major hsp100-/- alters the immune response in mice. Infect Immun 2006, 74(11):6027-6036.

44. Engwerda CR, Smelt SC, Kaye PM: An in vivo analysis of cytokine production during Leishmania donovani infection in scid mice. Exp Parasitol 1996, 84(2):195-202.

45. Leclercq V, Lebastard M, Belkaid Y, Louis J, Milon G: The outcome of the parasitic process initiated by Leishmania infantum in laboratory mice: a tissue-dependent pattern controlled by the Lsh and MHC loci. I Immunol 1996, 157(10):4537-4545.

46. Melby PC, Chandrasekar B, Zhao W, Coe JE: The hamster as a model of human visceral leishmaniasis: progressive disease and impaired generation of nitric oxide in the face of a prominent Th1-like cytokine response. J Immunol 2001, 166(3):1912-1920.

47. Gifawesen C, Farrell JP: Comparison of T-cell responses in self-limiting versus progressive visceral Leishmania donovani infections in golden hamsters. Infect Immun 1989, 57(10):3091-3096.

48. Dantas-Torres F: Canine leishmaniosis in South America. Parasit Vectors 2009, 2(Suppl 1):S1.

doi:10.1186/1756-3305-4-150

Cite this article as: Carrión et al:: Leishmania infantum HSP70-Il null mutant as candidate vaccine against leishmaniasis: a preliminary evaluation. Parasites \& Vectors 2011 4:150.

\section{Submit your next manuscript to BioMed Central and take full advantage of:}

- Convenient online submission

- Thorough peer review

- No space constraints or color figure charges

- Immediate publication on acceptance

- Inclusion in PubMed, CAS, Scopus and Google Scholar

- Research which is freely available for redistribution

Submit your manuscript at www.biomedcentral com/submit
Biomed Central 